\title{
Reduction and Management of No-Shows by Family Medicine Residency Practice Exemplars
}

\author{
Bradley J. Jobnson, $M D^{1}$ \\ James W. Mold, MD, MPH \\ J. Michael Pontious, $M D^{3}$ \\ ${ }^{1}$ Department of Internal Medicine, Univer- \\ sity of Oklahoma Health Sciences Center, \\ Oklahoma City, Okla \\ ${ }^{2}$ Department of Family and Preventive \\ Medicine, University of Oklahoma Health \\ Sciences Center, Oklahoma City, Okla \\ ${ }^{3}$ Garfield County Family Practice Residency \\ Program, Enid, Okla
}

\begin{abstract}
PURPOSE We wanted to describe the methods used by family medicine residency practices with low no-show rates (rate exemplars) and those able to keep visit rates high despite no-shows (management exemplars).

METHODS Program directors of US family medicine residency programs were asked to respond to a survey questionnaire. Telephone interviews were conducted with the administrators of rate exemplars (no-show rates of $10 \%$ or less) and management exemplars (average of 8 to 10 patient visits per half-day plus high administrator satisfaction with no-show management strategies).

RESULTS Directors of 14 rate and 8 management exemplars, identified from among the 141 practices (31.5\%) that returned the initial survey instrument, were interviewed and subsequently resurveyed. All of the rate exemplars used multiple strategies, including patient education, patient reminders, patient sanctions, and some degree of open-access scheduling. Practices that managed no-shows well encouraged walk-ins and work-ins and overbooked resident schedules either equally or based upon individual no-show rates. Practice exemplars of both types were highly committed to addressing the no-shows problem and were diligent about following their policies and procedures regarding no-shows.
\end{abstract}

CONCLUSION Some family medicine residency practices are able to achieve low no-show rates or keep them from affecting practice volume. Those that do use combinations of well-established methods.

Ann Fam Med 2007;5:534-539. DOI: 10.1370/afm.752.

\section{INTRODUCTION}

$\mathrm{P}$ atients' failure to keep scheduled appointments (no-shows) is a major problem in family medicine residency practices. Prior research has focused either on predictors of no-shows ${ }^{1-10}$ or the effectiveness of individual strategies, such as postcard reminders or variations in scheduling, for reducing no-show frequency ${ }^{11-17}$ or impact. ${ }^{18,19}$

Using best practices research, ${ }^{20}$ a technique to gather and combine effective management strategies used by practice exemplars, we attempted to identify the methods used by family medicine residency practices that have been able to achieve low no-show rates (rate exemplars) or that manage no-shows well when they occur (management exemplars).

\section{METHODS}

To identify a sufficient number of practice exemplars, a 1-page questionnaire was mailed to all allopathic family medicine residency program directors in the United States (448). The questionnaire asked the "most appropriate person" to estimate for their residency practice the following information: (1) the distribution of patients by age and by type of health insurance; 
(2) the average numbers of new and established patients seen, and the average number of no-shows per half-day; (3) the level of satisfaction with the current methods for reducing no-shows and for managing no-shows (5-point Likert scale); and (4) an assessment of the impact of noshows on resident education, continuity of patient care, patient access to care, and clinic income (5-point Likert scales). Respondents were given the option of supplying actual data from office records or estimates for that data. Finally, using an open-ended free-text response, they were asked to briefly describe their methods for reducing and managing no-shows. Respondents could return the questionnaire by facsimile or by completing a Web-based questionnaire. Nonrespondents were contacted again by e-mail after 4 weeks and 15 weeks.

A no-show was defined as "missing a scheduled appointment without calling to cancel." The no-show rate for each program was calculated as the ratio of noshows to total patients scheduled per half-day. Based upon the distribution of no-show rates across practices, we arbitrarily defined exemplary practices as those with rates equal to or below $10 \%$.

Management of no-shows was defined as "reducing the impact of no-shows once they occur." We defined management exemplars as practices in which residents saw an average of 8 to 10 patients per half-day session on average (including all 3 years), and the clinic director or program director was "satisfied" or "very satisfied" with their strategy for managing no-shows. Our assumption was that 8 to 10 patients per half-day for all residents was optimal for resident education. A much higher number of patients was seen in some residency practices.

Though not the primary focus of the study, descriptive statistics were calculated for all variables captured by the survey. Pearson correlation coefficients were calculated for relationships between no-show rates and continuous variables. Spearman correlation coefficients were calculated for relationships between no-show rates and Likert scale variables. Comparisons between Likert scale variables were made using the Kruskal-Wallis test. Variables potentially associated with no-show rates $(P<.2)$ were entered into a linear regression model with no-show rate as the dependent variable. A stepwise subtraction method was used to identify the most parsimonious model. All statistical calculations were done using Statistix v8.0 (Analytic Software, Inc, Tallahassee, Florida).

One investigator (J.M.) interviewed the practice administrators or medical directors from program exemplars by telephone, using a structured interview protocol, to obtain more information about their strategies for reducing and managing no-shows. Responses were captured through note-taking and summarized in writing immediately after each telephone interview.

Interview notes were analyzed by all 3 authors, who agreed upon categories and subcategories of interventions. These categories were then used to create a practice exemplar survey instrument listing the techniques mentioned by at least 1 director of a practice exemplar for reducing no-shows or managing noshows. All interviewees were asked to indicate which of the techniques they used. All but 1 responded. For that practice, interview data was used to complete the exemplar questionnaire.

We used the $\chi^{2}$ test to compare the proportions of practice exemplars of each type (rate exemplars and management exemplars) that used specific methods with the proportions of practices that were not exemplars (ie, exemplars of the other type only and the practices disqualified as exemplars after telephone interviews) that used those methods. We also compared free-text responses on the initial questionnaire between the top and bottom $10 \%$ of performers and created a linear regression model to look at associations between reported no-show reduction methods and no-show rates.

\section{RESULTS}

\section{Survey Data}

Questionnaires were sent to 448 residency program directors. Seventy practices responded to the first request, 44 to the second, and 27 to the third, for a total response rate of $31.5 \%$. Thirty-nine percent of the responses were by facsimile, and $61 \%$ were Web-based responses. There was no association between no-show rate and whether programs responded to the first, second, or third request. On average, however, later respondents saw fewer patients per half-day $(P=.03)$ and tended to view no-shows as less of a problem $(P=.09)$.

Descriptive statistics for the questionnaire variables are shown in Table 1. Two-thirds of the programs provided estimates, whereas one-third provided actual data. Those providing actual data had slightly lower mean no-show rates $(15 \%$ vs $17 \%, P=.15)$. Respondents were more concerned about the impact of no-shows on patient care (both access and continuity) and practice income, than on resident education $(P<.001$ for difference in medians).

\section{No-Show Rates}

The respective mean and median no-show rates were $17 \%$ and $15 \%$ (range $3 \%$ to $42 \%$ ). After adjusting for other variables, practices with higher proportions of new patients $(P=.03)$, Medicare patients $(P=.008)$ and self-pay patients $(P=.001)$ were more likely to have higher no-show rates, and those with a higher proportion of patients aged 46 to 64 years $(P=.002)$ were 
more likely to have lower no-show rates. No-show rates were not associated with the proportion of pediatric or Medicaid patients.

Practices with higher no-show rates judged the impact of no-shows on continuity of care $(P=.002)$, patient access to care $(P=.04)$, and practice income $(P=.007)$ to be greater than did practices with lower no-show rates. The positive association between noshow rate and perceived impact on resident education nearly reached statistical significance $(P=.06)$. No-show rates were not associated with level of administrator satisfaction with methods used to reduce no-show rates.

\section{Rate Exemplars}

Twenty-six (19\%) practices had no-show rates of $10 \%$ or less. Seventeen practice directors agreed to an interview, and 14 interviews were completed. (Scheduling conflicts and time limitations accounted for inability to interview the rest.) Three of those interviewed actually had no-show rates of more than 10\%, leaving 11 qualified interviewees. Six of these practices were located in large cities (populations greater than 100,000), 1 was in a suburban area, 2 were in moderate-sized nonsuburban towns

\begin{tabular}{|c|c|c|c|}
\hline Variable & Mean (SD) & Median & Range \\
\hline \multicolumn{4}{|l|}{ Patients' health insurance type } \\
\hline Medicaid, \% & $0.35(0.19)$ & 0.30 & $0.0-0.80$ \\
\hline Medicare, \% & $0.20(0.10)$ & 0.20 & $0.01-0.48$ \\
\hline Private insurance, \% & $0.31(0.21)$ & 0.27 & $0.01-1.00$ \\
\hline Self-pay, \% & $0.12(0.11)$ & 0.10 & $0.0-0.60$ \\
\hline \multicolumn{4}{|l|}{ Patients' age distribution } \\
\hline $0-18$ years, $\%$ & $0.23(0.11)$ & 0.20 & $0.02-0.60$ \\
\hline $19-45$ years, $\%$ & $0.30(0.11)$ & 0.30 & $0.1-0.75$ \\
\hline $46-64$ years, $\%$ & $0.27(0.10)$ & 0.25 & $0.03-0.60$ \\
\hline $65-79$ years, $\%$ & $0.16(0.09)$ & 0.15 & $0.0-0.55$ \\
\hline 80 years,$+ \%$ & $0.06(0.06)$ & 0.05 & $0.0-0.50$ \\
\hline \multicolumn{4}{|l|}{ Patients seen per half-day } \\
\hline New patients, $\mathrm{n}$ & $1.77(0.79)$ & 2.0 & $0-4$ \\
\hline Established patients, n & $7.08(2.02)$ & 7.0 & $1-12$ \\
\hline Total No. of patients, $n$ & $8.81(2.23)$ & 8.0 & $3.5-15$ \\
\hline No-shows per half-day, $\mathrm{n}$ & $1.83(0.98)$ & 2.0 & $0.4-5.0$ \\
\hline No-show rate, \% & $0.17(0.07)$ & 0.15 & $0.03-0.42$ \\
\hline \multicolumn{4}{|c|}{ Administrator satisfaction score* } \\
\hline Reducing no-shows & $2.79(1.00)$ & 3 & $1-5$ \\
\hline Managing no-shows & $2.93(0.97)$ & 3 & $1-5$ \\
\hline \multicolumn{4}{|l|}{ Impact of no-shows score ${ }^{\dagger}$} \\
\hline Overall & $3.05(1.20)$ & 3 & $1-5$ \\
\hline Resident education & $2.76(1.07)$ & 3 & $1-5$ \\
\hline Continuity of care & $3.06(1.11)$ & 3 & $1-5$ \\
\hline Access to care & $3.31(1.10)$ & 3 & $1-5$ \\
\hline Income & $3.09(1.05)$ & 3 & $1-5$ \\
\hline
\end{tabular}

(populations of 20,000 to 50,000), and 2 were in small rural areas. Three were at academic medical centers and 8 were not. The proportion of their patient populations insured by Medicaid ranged from $0 \%$ to $60 \%$ (median $36.5 \%$ ) with $0 \%$ to $20 \%$ (median $2.5 \%$ ) uninsured. None of the faculty or residents in the practice exemplars had published or presented (beyond their own group) anything about their methods for reducing no-shows.

The methods used by rate exemplars fell into 6 categories: patient education, patient reminders, sanctions, open access, emphasis on continuity, and scheduling rules (Table 2). All but 2 practices attempted to contact all patients within 24 to 48 hours of every appointment to remind them of the appointment. One practice administrator reported that "when a secretary, who had been telephoning all of the patients the day before their appointment, decided to stop doing so (without telling her supervisors), the no-show rate went from 5\% to $10 \%$ within 1 week." Of the 2 practices that did not telephone to remind patients, 1 had a complete openaccess scheduling system. This clinic manager reported, "our no-show rate, which was $25 \% 2$ years ago, went to $9 \%$ when we began calling every patient the day before their appointment and added a walk-in clinic, and to $4 \%$ when we converted to an open-access scheduling system."

Several directors of the rate exemplars described in detail their policies for patients who did not keep appointments, some of which were crafted with great care in consultation with attorneys. For the most part, these policies included the following steps: (1) forewarning of the policy (upon joining the practice and/or when scheduling or being reminded of an appointment, (2) a system for tracking and documenting no-shows in the medical record and in the appointment system, (3) notification of the physician of all no-shows, (4) a telephone call after each no-show, (5) warning letters after each of the first 2 no-shows, and (6) a dismissal letter after the third no-show in 6 months. When asked to estimate the percentage of patients who, after missing appointments 3 times within a 6 months, are actually dismissed, most estimated greater than $90 \%$. By the end of the rate exemplar interviews, no new methods were being reported, suggesting that we had reached saturation.

Rate exemplars did not differ substantially from the other practices, whose directors were interviewed, with respect to types or numbers of no-show reduction strategies used. Based upon the original 
survey responses, the $10 \%$ of practices with the highest no-show rates were somewhat more likely to call all or high-risk patients to remind them of appointments ( $75 \%$ vs $55 \%)$, but this difference did not reach statistical significance. Logistic regression analysis found no

Table 2. Strategies Used by Exemplary Practices to Reduce No-Shows Rates $(n=11)$

\begin{tabular}{lc}
\hline & $\begin{array}{c}\text { Practices } \\
\text { Using Method } \\
\text { No. (\%) }\end{array}$ \\
\hline Patient education & $10(91)$ \\
On enrollment in practice & $7(64)$ \\
When each appointment is made & $6(55)$ \\
When reminded of appointment & $4(36)$ \\
After each no-show & $7(64)$ \\
After repeated no-shows & $5(45)$ \\
No. of education strategies, median (range) & $3(0-5)$ \\
Patient reminders & $9(82)$ \\
Telephone call to all patients & $9(82)$ \\
Telephone call to high-risk patients & $2(18)$ \\
Letter/card to all patients & $1(9)$ \\
Letter/card to high-risk patients & $1(9)$ \\
No. of reminder strategies, median (range) & $1(0-3)$ \\
Patient sanctions & $9(82)$ \\
Expelled from practice & $9(82)$ \\
Required to walk-in (no appointments) & $1(9)$ \\
Open access* & $9(82)$ \\
Complete & $3(27)$ \\
Partial (lots of work-in slots) & $6(55)$ \\
Continuity emphasis & $7(64)$ \\
Residents work in small teams & $2(25)$ \\
Scheduling rules & \\
Residents cannot schedule appointments & week ahead; com- \\
Work with individual residents & \\
\hline *open access defined as no appointments made beyond & \\
\hline
\end{tabular}

Table 3. Strategies Used by Management Exemplar Practices $(n=8)$

\begin{tabular}{lc} 
Method & $\begin{array}{c}\text { Practices } \\
\text { Using Method } \\
\text { No. (\%) }\end{array}$ \\
\hline Overbooking & $5(63)$ \\
Overbook all residents equally & $3(38)$ \\
Overbook based upon no-show rate & $2(25)$ \\
Overbook high-risk patients & $2(25)$ \\
Walk-ins and work-ins & $8(100)$ \\
Encourage/allow walk-ins/work-ins & $7(88)$ \\
Make high-risk patients* walk-in/work-in & $2(25)$ \\
Adjust schedule to demand & $2(25)$ \\
See all patients wanting to be seen & \\
\hline * Patients more likely to miss a scheduled appointment. & \\
\hline
\end{tabular}

significant relationship between no-show rates and freetext reports of telephoning to remind all patients, openaccess scheduling, or patient dismissal for no-shows.

\section{Management Exemplars}

Mean patient visits per half-day for all survey respondents was 8.81 (median 8). Twenty-two clinic directors $(16 \%)$ reported visit rates of 8 to 10 patients per half-day and high levels of administrator satisfaction with the methods they were using to manage no-shows. Of these directors, 14 agreed to be interviewed and 8 interviews were completed. In this case, all practices met the criteria for exemplar status. Three of the 8 management exemplars were also rate exemplars. All management exemplars were affiliated with an academic medical center. None had published or presented their no-show methods. All but 1 practice was located in a large city. The proportion of Medicaid patients ranged from $30 \%$ to $60 \%$, with a median of $50 \%$.

The methods used by management exemplars are shown in Table 3 . The 8 practice exemplars were more likely than the practices that were not exemplars to overbook all residents $(P=.02)$. Based upon initial survey responses, the top $10 \%$ of management exemplars appeared to be more likely to fill no-show slots with walk-ins and work-ins or to overbook (40\% vs $10 \%)$, but this difference was not statistically significant.

\section{Additional Qualitative Perceptions}

The interviewer noted that administrators of practice exemplars in both categories seemed to be committed to reducing the number or impact of no-shows. They spoke of running "a tight ship," of being "very concerned about no-shows," and of developing "special committees" to deal with the problem. All were able to produce exact numbers and percentages for the requested variables, and they were very much interested in finding out what other practices were doing to address no-shows.

In all practices included in the exemplar interviews, residents and faculty practiced together, which in most, but not all cases, the administrators believed raised the stature of the practice in the community and reduced no-show rates.

\section{DISCUSSION}

The impact of no-shows on residency program practices has not been well-documented. Bigby and colleagues were unable to confirm a detrimental effect on patient outcomes. ${ }^{21}$ Anecdotal evidence would suggest, however, that patients are affected by a decrease in appointment availability secondary to slots filled by no-shows, and that no-show patients are affected by the break in continuity of care. In our study, both no- 
show rates and levels of concern about their impact on resident education, continuity of care, access to care, and practice income varied widely among respondents. Survey respondents in general were more concerned about the impact of no-shows on patients and the practice than on resident education, but this finding could have been a function of who completed the questionnaires (administrators vs faculty). ${ }^{4}$

Prior research has suggested that in primary care residency program practices, those more likely to miss scheduled appointments are younger adult, ${ }^{1,4-6}$ unmarried $^{5}$ nonwhite patients ${ }^{4,6}$ who have larger families and less education ${ }^{22,23}$ and whose language, race, or sex is not concordant with that of the clinician ${ }^{2}$; patients who have no insurance ${ }^{5}$ or are on Medicaid ${ }^{4}$; patients new to the practice ${ }^{5}$; patients referred from the emergency department $^{7}$; patients with acute rather than chronic illnesses ${ }^{5}$; patients scheduled with first-year residents or medical students ${ }^{4}$; patients with a history of missed appointments ${ }^{1,6,7} ;$ and patients with physician-identified psychosocial problems. ${ }^{3,6}$ Our findings support some of these associations (no insurance, new patients) but not others (Medicaid, young adults). Interestingly, only 3 of the 11 rate exemplars $(27 \%)$ and 4 of the 8 management exemplars $(50 \%)$ used this kind of information from previous research to inform practice strategies.

No-shows have also been found to be associated with longer intervals between visits ${ }^{7,8,11}$ and confusion regarding the reason for the follow-up appointment. ${ }^{24}$ Based on this information, Bigby and colleagues suggested that no-show rates might be reduced by negotiating follow-up appointments with patients. ${ }^{21}$ Several of the rate exemplar interviewees suggested the importance of negotiating a return appointment interval with each patient, speculating that some of the variability in no-show rates between residents could be explained by how well they negotiate, but only one practice had devoted time specifically to teaching residents this skill.

Open-access scheduling has been suggested as a way to improve patient flow and increase continuity of care and patient satisfaction. ${ }^{25-27}$ An open-access system may better meet the needs of patients who tend to miss appointments. ${ }^{28}$ Two practice exemplar interviewees reported that no-show rates dropped by $50 \%$ after they converted to an open-access scheduling system. In one of the only published controlled trials of openaccess vs traditional scheduling in a residency practice, however, there was no significant difference in noshow rates at the end of the study, though no-show rates were low (approximately $8 \%$ ) in both intervention and control groups. ${ }^{12}$

When asked why they missed appointments, patients have reported, among other things, the perception that the practice did not respect them and lack of transportation as contributing factors. ${ }^{9,10}$ A number of the rate exemplar directors mentioned that their practices, for a variety of reasons, were held in high regard within their communities. None of these practices provided transportation for patients.

We have previously used best practices research to identify practice exemplars and the methods used to deliver pneumococcal vaccine, ${ }^{20}$ manage laboratory test results, ${ }^{29}$ handle prescription refills, ${ }^{30}$ and care for patients with diabetes. ${ }^{31}$ This study extends this work to reduction and management of no-shows in residency practices. Although the best practices approach is attractive for a number of reasons, it has limitations. ${ }^{20}$ Success in practice is generally due both to the methods used and to characteristics of those who use them. ${ }^{32}$ In this study, we could not identify any single strategy or combination of strategies different from the methods used by less successful practices. Though the interviews left us with the impression that the practice exemplars were extremely diligent about implementation and monitoring of the methods they chose to use, we cannot be certain such was the case or that it was different from practices not found to be exemplars.

This particular study has additional limitations. The response rate to the initial survey was only $31.5 \%$. Those who completed the questionnaire varied in their roles with the practices: some were clinic administrators, some medical directors, and some residency directors. Estimates regarding patient characteristics and practice performance were confirmed only for those interviewed, during which errors were identified in approximately onethird of the cases. Also, our estimation of no-show rates in the questionnaires included walk-in patients in the denominator. Because walk-in patients technically could not be a no-show, the calculated no-show rates would be falsely reduced in practices with more walk-in patients.

No attempt was made to interview the lowest performers for comparison, as our stated purpose was to describe successful approaches. It is possible, however, that we might have uncovered other, more subtle differences or better recognized ineffective strategies had we done so.

We conclude that it is possible to reduce no-show rates in residency practices to below 10\% using combinations of well-established methods if they are carried out consistently and effectively. Reducing the impact of no-shows once they occur seems to be best accomplished by increasing the numbers of walk-in and workin patients. We certainly acknowledge the possibility that the practice exemplars may have been doing other things that neither they nor we were able to discern. We hope that the results of this study will contribute to the existing literature on no-shows in primary care residency program practices and will be helpful to 
those who are struggling with this important challenge. The degree to which our findings can be generalized to nonresidency practices is unclear, though we hope that our findings in combination with the other information reviewed in the Discussion section will be helpful to all primary care clinicians struggling with this issue.

To read or post commentaries in response to this article, see it online at http://www.annfammed.org/cgi/current/full/5/6/534.

Submitted April 4, 2007; submitted, revised, July 9, 2007; accepted July 11,2007

Key words: Appointments and schedules; workload; office management; no-show; primary health care; internship and residency; best practice analysis

Funding support: Department of Family and Preventive Services, University of Oklahoma.

Acknowledgments: The authors would like to recognize the contributions of the following clinic directors and residency program faculty to this project: Fredrick Edwards, MD, Scottsdale, Arizona; Janet Noel, Muncie, Indiana; Kathy Bakke, MD, Klamath Falls, Oregon; Sharon Armstrong, Vancouver, Washington; Ken Vellequette, Sylvania, Ohio; Teresa Foulke, Johnson City, Tennessee; Tammy Ralston, Columbia, Missouri; Suzanne Anderson, Scottsdale, Ariz; Brad Winslow, MD, Littleton, Colorado; Brenda Bacon, Lincoln, Nebraksa; Shannon Morgan, MD, Mobile, Alabama; Joane Baumer, MD, Ft. Worth, Texas; Judy Ward, Redding, California; Carlos Dumas, MD, Houston, Texas; Thomas Byrne, MD, Boston, Massachusetts; Marla Vance, Little Rock, Arkansas; Suzie Baker, McAllen, Texas; Jackie Gregor, Toledo, Ohio; Chuck Fitch, Quincy, Illinois; Sue Littlewood, Tallahassee, Florida; and Nancy Weingarten, Augusta, Maine. We also want to acknowledge Candace Lacy for all the time spent scheduling and rescheduling interviews and Lavonne Glover for her assistance with manuscript preparation.

\section{References}

1. Neal RD, Hussain-Gambles M, Allgar VL, Lawlor DA, Dempsey O. Reasons for and consequences of missed appointments in general practice in the UK: Questionnaire survey and prospective review of medical records. BMC Fam Pract. 2005;6:47.

2. Lasser KE, Mintzer IL, Lambert A, Cabral H, Bor DH. Missed appointment rates in primary care: the importance of site of care. J Health Care Poor Underserved. 2005;16(3):475-486.

3. Cashman SB, Savageau JA, Lemay CA, Ferguson W. Patient health status and appointment keeping in an urban community health center. J Health Care Poor Underserved. 2004;15(3):474-488.

4. Weingarten N, Meyer DL, Schneid JA. Failed appointments in residency practices: Who misses them and what providers are most affected? J Am Board Fam Pract. 1997;10(6):407-411.

5. Gruzd DC, Shear CL, Rodney WM. Determinants of no-show appointment behavior: The utility of multivariate analysis. Fam Med. 1986;18(4):217-220.

6. Goldman L, Freidin R, Cook F, Eigner J, Grich P. A multivariate approach to the prediction of no-show behavior in a primary care center. Arch Intern Med. 1982;142(3):563-567.

7. Hofmann PB, Rockart JF. Implications of the no-show rate for scheduling OPD appointments. Hosp Prog. 1969;50(8):35-40.
8. Hagerman GA. Testing the mailed appointment reminder in family practice. J Fam Pract. 1978;7(1):199-201.

9. Lacy NL, Paulman A, Reuter MD, Lovejoy B. Why we don't come: patient perceptions on no-shows. Ann Fam Med. 2004;2(6):541-545.

10. Little B, Cannon C, Whitson B, Jarolim DR. The failed appointment. J Okla State Med Assoc. 1991;84(9):455-458.

11. Shroeder SA. Lowering broken appointment rates at a medical clinic. Med Care. 1973;11(1):75-78.

12. Belardi FG, Weir S, Craig FW. A controlled trial of an advanced access appointment system in a residency family medicine center. Fam Med. 2004;36(5):341-345.

13. Benjamin-Bauman J, Reiss ML, Bailey JS. Increasing appointment keeping by reducing the call-appointment interval. J Appl Behav Anal. 1984;17(3):295-301.

14. Bigby J, Giblin J, Pappius EM, Goldman L. Appointment reminders to reduce no-show rate. JAMA. 1983;250(13):1742-1745.

15. Guse CE, Richardson L, Carle M, Schmidt K. The effect of exitinterview patient education on non-show rates at a family practice residency clinic. J Am Board Fam Pract. 2003;16(5):399-404.

16. Hashim MJ, Franks P, Fiscella K. Effectiveness of telephone reminders in improving rate of appointment kept at an outpatient clinic: A randomized controlled trial. J Am Board Fam Pract. 2001;14(3):193-196.

17. Quattlebaum TG, Darden PM, Sperry JB. Effectiveness of computergenerated appointment reminders. Pediatrics. 1991;88(4):801-805.

18. Izard T. Managing the habitual no-show patient. Fam Pract Manag. 2005;12(2):65-66.

19. Shonick W, Klein BW. An approach to reducing the adverse effects of broken appointments in primary care systems. Med Care. 1977;15(5):419-429.

20. Mold JW, Gregory ME. Best practice research. Fam Med. 2003;35(2):131-134.

21. Bigby JA, Pappius E, Cook EF, Goldman L. Medical consequences of missed appointments. Arch Intern Med. 1984;144(6):1163-1166.

22. Hertz P, Stamps PL. Appointment-keeping behavior re-evaluated. Am J Public Health. 1977;67(11):1033-1036.

23. Hurtado AV, Greenlick MR, Colombo TJ. Determinants of medical care utilization: Failure to keep appointments. Med Care. 1973;11(6):189-198

24. Frankel S, Farrow A, West R. Non-attendance or non-invitation? A case-control study of failed outpatient appointments. BMJ. 1989;298(6684):1343-1345.

25. Kennedy JG, Hsu JT. Implementation of an open access scheduling system in a residency training program. Fam Med. 2003;35(9):666-670.

26. White B. Starting a revolution in office-based care. Fam Pract Manag. 2001;8(9):29-35.

27. Murray M, Tantau C. Same-day appointments: Exploding the access paradigm. Fam Pract Manag. 2000;7(8):45-50.

28. Virji A. A study of patients attending without appointments in an urban general practice. BMJ. 1990;301(6742):22-26.

29. Mold JW, Cacy DS. Management and reporting of laboratory test results in family practice: an OKPRN Study. J Fam Pract. 2000;49(8):709-715.

30. Ferrell CW, Aspy CB, Mold JW. Management of prescription refills in primary care: an Oklahoma Physician Resource/Research Network (OKPRN) Study. J Am Board Fam Pract. 2006;19(1):31-38.

31. Nagykaldi Z, Mold JW. Diabetes patient tracker, a personal digital assistant-based diabetes management system for primary care practices in Oklahoma. Diabetes Technol Ther. 2003;5(6):997-1001.

32. Gawande A. The bell curve. The New Yorker. Dec 6, 2004 